\title{
Prevalence of Blood Pressure among Green Coffee Users of Young and Middle Age Saudis
}

\author{
Ilham Abdalla Bashir Fadl, Gul Mohamed Rasitha Banu, Khloud Abdullrhman Damri, Bsmah \\ Waheed Hussin, Shatha Abdullah Mubarki, Alaa Mohammed Moqri
}

\begin{abstract}
This is an analytical descriptive cross-section study. It was conducted among youth Saudis coffee consumers. It aimed at detecting the coffee consumption patterns (coffee type, concentration, volume/day, time length, site, water drink after coffee intake) concerning the onset of high BP, and signs and symptoms suggesting its presence. The hypothesis is the presence of significant inter-relation between them.Non-probability convenient sampling was applied; a self-administered questionnaire was developed, tested and filled by 340 males and females students, their relatives, besides the Faculty of Public and Tropical Medicine administrative staff. Findings showed that a total of $50(14.7 \%)$ respondents reported having high BP. Of them, 29 (58\%) were users of Arabica coffee (only), while 49 (98\%) used the Arabica coffee along with other coffee types. The OR showed that the consumers of Arabica coffee (only) were at 1.79 risks of contracting high $\mathrm{BP}$, while the favorites of each of the concentrated, and the homemade coffee were at 1.5 and 2.1 risks respectively. The homemade predictor value was significantly $(P<0.05)$ related to high BP. Apart from the intake of Arabica coffee (only), the OR of all coffee consumption patterns were seen to be prognosis factors of contracting 4+signs and symptoms suggesting high blood pressure. But, no significant (P>0.05) relation was there. Familial history of high $B P$, and below university $O R$ were at 1.7 and 1.9 risks of contracting high $B P$ respectively. However, no significant $(P>0.05)$ relation was there.The conclusion is that the consumers of Arabica coffee (only) were almost 2 times the risk of contracting high BP. Each of the homemade and strong coffee was seen to be prognosis factors of both contracting high BP and of having 4+ signs and symptoms suggesting its presence.
\end{abstract}

Keywords: High Blood Pressure, homemade coffee, coffee consumption patterns, coffee types, coffee intake, strong coffee.

\section{INTRODUCTION}

The effect of coffee consumption patterns on raising $\mathrm{BP}$ and experiencing of signs and symptoms suggesting high BP is not certain. The study aimed at aimed at investigating the coffee consumption patterns that predict the onset of high BP and/or SIGNS and symptoms suggesting it's presence among youth and middle age Saudis. The research question was how much different patterns of coffee consumption would predict the onset of high BP? its measurable objectives were: 1-to determine the socio-demographic background of the study

Revised Manuscript Received on December 05, 2019.

Ilham Abdalla Bashir Fadl, Health Informatics Department, Faculty of Public and Tropical Medicine - Jazan University- Jizan,Saudi Arabia.

Gul Mohamed Rasitha Banu, Health Informatics Department, Faculty of Public and Tropical Medicine - Jazan University- Jizan,Saudi Arabia.

Khloud Abdullrhman Damri, Health Informatics Department, Faculty of Public and Tropical Medicine - Jazan University- Jizan,Saudi Arabia

Bsmah Waheed Hussin, Health Informatics Department, Faculty of Public and Tropical Medicine - Jazan University- Jizan,Saudi Arabia.

Shatha Abdullah Mubarki, Health Informatics Department, Faculty of Public and Tropical Medicine - Jazan University- Jizan,Saudi Arabia.

Alaa Mohammed Moqri, Health Informatics Department, Faculty of Public and Tropical Medicine - Jazan University- Jizan,Saudi Arabia. group, 2- to identify patterns of coffee consumption in term of: type, concentration, intake site, volume, time span of coffee intake, and coca-cola intake as a caffeine containing products and to 3 - to predict the effect of those patterns on the onset of BP and /or risk factors suggestin its presence.

World Health Organization (WHO) defined BP as Hypertension, also known as high or raised BP, is a condition in which the blood vessels have persistently raised pressure. Each time the heartbeats, it pumps blood into the vessels. BP is created by the force of blood pushing against the walls of blood vessels (arteries) as it is pumped by the heart. The higher the BP the harder the heart has to pump blood into vessels [1].

\section{LITERATURE REVIEW}

John Warner stated that evidence for hypertensive cardiomyopathy is that one of the following conditions must be met: Untreated systolic BP greater than $160 \mathrm{~mm} \mathrm{Hg}$ or diastolic greater than $105 \mathrm{~mm} \mathrm{Hg}$ for at least 3 months. Hypertension requiring at least 2 drugs for control for at least 5 years, presence of diabetes and hypertension, treated or untreated, Documented left ventricular hypertrophy (preferably by echocardiography or MRI) and absence of other etiologies for heart failure. [2].

\section{A. Coffee}

Coffee and other caffeine-containing beverages are widely consumed on a daily basis over the world. Coffee is a popular drink global wide, when analyzing the consumption of coffee worldwide, it is found that the consumption of coffee in Nordic countries is among the highest in the world. In Denmark the daily average caffeine consumption is around $7 \mathrm{mg} / \mathrm{kg}$, while in United States coffee. Students, aged between 19 and 30 especially females, that consume more caffeine than the population average but less than those between the ages of 31 and 50. It is also reported that coffee ranks $24^{\text {th }}$ among Koreans' daily foods in terms of energy consumption and that Koreans drink more coffee than rice and other local foods.[3]

\section{B. Coffee chemistry}

Understanding coffee chemistry is easier by remembering that a coffee bean is the seed of a coffee plant and as such it can be expected to contain a full range of plant cell materials The cell walls of cellulose, hemo-clucose, and pectin are built in varying amounts of lignin, tannins, gums, proteins and minerals. Robusta contains nearly twice as many caffeine as in the Arabica coffee. 
The fatty part of coffee consists mainly of triglycerides, steroids, and tocopherol, the typical ingredients found in all edible vegetable oils. In addition, so-called coffee oil contains the diterpenes of the Corin family at rates up to $20 \%$ of the total fat.

Diterpenes were having analytical and physiological effects in the composition of the main fatty components of the two most important coffee types, coffee Arabica and coffee canephora var. [4]

\section{Caffeine intake and physical performance}

Barone etal repored the effect of caffeine intake on physical performance, muscle strength, endurance, and intensity in sports games appear after doses exceeding $200 \mathrm{mg}$ (3 mg-1 $\mathrm{kg}$ ). There are many occupations in the army, transport workers, factory shift workers, and jobs with that requires the best physical and cognitive structures, workplace safety and productivity, conditions, which may include restricted sleep, repeated use of caffeine is an effective strategy for securing physical and cognitive abilities [5] .

\section{Health risks of caffeine and coffee intake}

Andersen etal study concluded that the consumption of coffee is a major source of dietary antioxidants, may inhibit inflammation and thereby reduce the risk of cardiovascular and other inflammatory diseases in postmenopausal women [6]. It is very important to recognize the possible threats and benefits in link with caffeine consumption by both health professionals and the public. Nurminen etal reported that in epidemiological studies, causal relationships were difficult to prove. However, recent studies have shown a significant impact on heart disease atherosclerosis when drinking coffee for long and consecutive periods. Contrary to what is commonly believed, that coffee and/or caffeine consumption can cause heart disease, literature in publication provides little evidence that the consumption of coffee and/or caffeine at moderate doses may increase the risk of Myocardial infarction, sudden death or irregular heartbeat [7].

Higdon etal reported that there is little evidence of health risks and some evidence of health benefits however, possible health risk of coffee intake, for adults consuming moderate amounts of coffee (3-4 cups/d providing 300-400 mg/d of caffeine), and some groups, including people with hypertension, children, adolescents, and the elderly, may be more vulnerable to the adverse effects of caffeine [8].

O'Keefe etal reported that coffee consumption may reduce the risk of type 2 diabetes and high BP, as well as other conditions associated with the risk of heart disease, dysmenorrheal, and depression. From another side, coffee consumption may affect fat profiles depending on how is it prepared. A potential benefit of coffee is its protection against neurodegenerative diseases, asthma, and reduced risk of gastrointestinal disease as well. A reasonable amount of coffee per day ( 2 to 3 cups) is safe and that it has beneficial effects of most health outcomes. However, most of the data on the health effects of coffee are based on observational data; very few randomized studies are available. In addition, the potential benefits of regular coffee are that the amount of consumption should be balanced against potential risks on insomnia, palpitations on bone and may increase the risk of bone fractures due to its high caffeine content [9].

Palatini etal examined a total of 553 young white prospective individuals were examined for stage 1 hypertension. The intake of coffee was checked regularly by questionnaires, the study found that urinary epinephrine was higher in coffee drinkers than abstainers. Conclusion show that the risk of hypertensive associated with coffee intake varies according to CYP1A2 genotype [10]. Nurminen etal concluded that habitual coffe intake may be risky to some hypertensive-prone subjects and that the hemodynamic effects of chronic coffee and caffein consumption is not thoroughly studied. Inclusion of cardiovascular block mighr ocuurs as a resulr of caffien effect of sdenosine receptors and inhibition of phosphodiesterases [11]. Gadsby etal reported that, although caffeine consumption is associated with increased BP, the relationship between caffeine and BP is not well defined. They also reported that too much consumption of coffee (five or more cups a day) can cause a small increase in $\mathrm{BP}(\mathrm{BP})(2 / 1 \mathrm{~mm} \mathrm{Hg})$ whether having BP or not, especially if combined with a prolonged intake that can go up to several months. They recommended that excessive consumption of caffeine-rich products or coffee should not be promoted until checking for their BP. Although medical research has not confirmed this, some suggested co-link between them [12]. In Robertson study, it was observed that after one hour of caffeine intake, it was observed that an increased in respiratory rate by $20 \%$ is associated with plasma caffeine levels. The conclusion is that the usual caffeine intake can causes similar effects still need to be investigated [13]

Kozuma etal study reported that the water-soluble green coffee bean extract (GCE) has been shown to be effective against hypertension in both spontaneously hypertensive rats and humans. Both BP were significantly reduced in a dose-related manner. Adverse effects caused by GCE were not observed. The results suggested that daily use of GCE has a BP lowering effect in patients with mild hypertension [14]. Landin paper summarizes the current epidemiological evidence on coffee consumption in relation to BP and risk of hypertension. Data from cross-sectional studies suggest an inverse linear or U-shaped association of habitual coffee use with BP in different populations. The study concluded that despite the precise nature of the relation between coffee and $\mathrm{BP}$ is still uncertain, however, most evidence suggests that regular intake of caffeinated coffee does not increase the risk of hypertension [15].

The randomized controlled trials conducted by Geleijnse, reported the presence of several underlying biological mechanisms that attributed to BP-raising effects of caffeine. Many beneficial substances in coffee, such as polyphenols, soluble and potassium, could exert effect in the cardiovascular system. Despite the fact that the exact relationship nature between coffee and BP is still unsure, most data suggests that habitual intake of caffeinated coffee does not increase the risk of hypertension [16].

The objectives of the a systematic review and meta-analysis conduct by Steffen et al of available randomized controlled trials (RCTs) and cohort studies to assess the effect of chronic coffee consumption on BP and the development of hypertension. The study concluded that recommendation with or against coffee consumption in relation to BP could not be made because of the quality of the evidence currently available. Besides, there were no statistically significant effects of coffee consumption on onset of BP or the risk of high BP [17]. 
Klag etal conducted a study to evaluate the coffee consumption in a group of 1017 Arab males who were former medical students and had an average age of 26 years from 1948 to 1964 . BP and hypertension were determined annually by self-report.

The results showed that consumption of one cup of coffee per day was increased the systolic BP by $0.19 \mathrm{mmHg}$ and the diastolic pressure by $0.27 \mathrm{mmHg}$. The study concluded that coffee drinking is insignificantly associated with rising BP, which plays a small role in the development of hypertension [18]

\section{E. Risk of Cardamom}

Verma conducted a study on elettaria cardamom Maton. Results showed that the administration of $3 \mathrm{~g}$ cardamom powder was significantly $(\mathrm{p}<0.001)$ decreased the systolic, diastolic and mean BP and significantly $(\mathrm{p}<0.05)$ increased fibrinolytic activity at the end of the three months. Findings also showed that the total antioxidant status was also significantly $(p<0.05)$ increased by $90 \%$ at the end of 3 months. However, fibrinogen and lipid levels were not significantly altered. All those involved in the study reported a feeling of well being without any side-effects. The study concluded that small cardamom can effectively reduce BP, enhances fibrinolysis and improves antioxidant status, without significantly altering blood lipids and fibrinogen, in stage 1 hypertensive patients [19]. In the Iranian registry of clinical trials; a study to identify the effect of cardamom on blood lipids, blood sugar indices, and BP in per-diabetic females was conducted. Observation shows no significant decrease in systolic and diastolic BP, glycemic indices, and serum lipids levels between the cardamom and the placebo group. The study concluded that the green cardamom supplementation may have a protective effect on the level of HDL-C (cholesterol) in pre-diabetic subjects. Fatemeh, 2017 concluded that green cardamom supplementation may have a protective effect on HDL-C level in pre-diabetic subjects. It improves some blood parameters in these subjects; however, its effects are not different from placebo [20]. Under the objective to identify the effects of daily consumption of Arabic coffee with cardamom adds, on BP, lipids, heart, and liver function biomarkers Badkook etal. conducted a study among (36) healthy adult females, non-smokers, non-alcoholics, and dyslipidemia aged 18 to 40 at King Abdul-Aziz university, Jeddah, Saudi Arabia. The study was last for a full month, Abstain from drinking coffee for at least eight hours to wash its' effects from their body. The participants were divided into three groups with three doses of cardamom adds to their daily coffee intake. The study concluded that, daily consumption of $500 \mathrm{ml}$ of Arabica coffee with either regular or high doses of cardamom may be a risk factor for the development of cardiovascular disease due to high TC (t-cytotoxic cell) which might cause the ischemic heart disease, and low-density lipoprotein cholesterol (LDL-C) indicating an increased risk of heart disease and stroke especially with a high dose of cardamom, although it does not affect BP and inflammation. Besides, its' beneficial effect on the liver enzyme was recorded [21].
This study hypotheses that high BP is inter-related with coffee consumption patterns and socio-demographic background. It aimed at detecting coffee consumption patterns and socio-demographics factors predicting high BP and signs and symptoms suggesting it's presence among Saudis aged $18-45$ years.

\section{METHOD}

This is an analytical community based cross sectional study that was conducted in Jazan region, kingdom of Saudi Arabia. Different rural and urban areas in the region were covered, besides, students and administrative staff enrolled in the Faculty of Public Health and Tropical Medicine and employees in the public and private sectors as well. All were Saudis, coffee concomersaged 18-45years. The study was conducted during January-February 2019. Non probability convenient sample was used to reach a total of 340 males and females individuals. A self administrated structured pre-coded questionnaire was developed, tested and used for data collection. It was self-administered by respondents. The questionnaire was composed of three sections; socio-demographic background, coffee consumption pattern and having BP and/or signs and symptoms suggesting its presence. Study accomplishment was approved and stamped by the faculty research unit and respondents consent was assured prior data collection. Pictorial images were included for the respondent to specify the cup size usually used in coffee drinking. All necessary arrangements (training, collection mechanisms of filled questionnaire...etc) were secured and executed as was planned. Data analysis was processed with the use of Statistical Package for Social Sciences (SPSS V. 24). Descriptive statistics and bilateral relations were generated. Correlations, regressions were computed by applying Chi-square test and multinomial logistic regression model to identify independently factors predicting the incidence of BP and/or signs and symptoms associated with its presence as a result of different patterns of coffee consumption. Significance of difference at $\mathrm{P}<0.05$ and odds ratios ware accomplished and graphs and tabulations were produced by the Excel Microsoft Programme.

\section{RESULTS}

\section{1- Coffee Type Preference of by Sex}

Table (1) shows the distribution of coffee preferred type by sex. Of the total reported their preference of Arabica coffee (155) respondents; 46 (29.7\%) were males while 109 (70.3\%) were females. Only 22 respondents reported their preference of black coffee; of them, $13(59.1 \%)$ were males while 9 $(40.9 \%)$ were females.

Table 1: Distribution of Preference of Coffee Type by Sex

\begin{tabular}{|c|c|c|c|c|c|c|c|}
\hline - & Male & $\%$ & Female & $\%$ & Total & $\%$ & Sig \\
\hline $\begin{array}{l}\text { Arabica } \\
\text { coffee }\end{array}$ & 46 & 29.7 & 109 & 70.3 & 155 & 100.0 & \multirow{5}{*}{$\mathrm{P}<0.05$} \\
\hline $\begin{array}{l}\text { Both } \\
\text { Arabica } \\
\text { and } \\
\text { black } \\
\text { coffee }\end{array}$ & 51 & 34.2 & 98 & 65.8 & 149 & 100.0 & \\
\hline $\begin{array}{l}\text { Black } \\
\text { coffee }\end{array}$ & 13 & 59.1 & 9 & 40.9 & 22 & 100.0 & \\
\hline $\begin{array}{l}\text { Other } \\
\text { types of } \\
\text { coffee }\end{array}$ & 3 & 21.4 & 11 & & & & \\
\hline Total & 113 & 33.2 & 227 & & 340 & & \\
\hline
\end{tabular}




\section{2-Incidence of Blood Pressure by Socio Demographic Background}

Figure [1] and table [2] shows that of the total males (113); 12 $(10.6 \%)$ reported having $\mathrm{BP}$ while $38(16.7 \%)$ of the total females (227).

\section{3-Incidence of Blood Pressure by Socio Demographic Background}

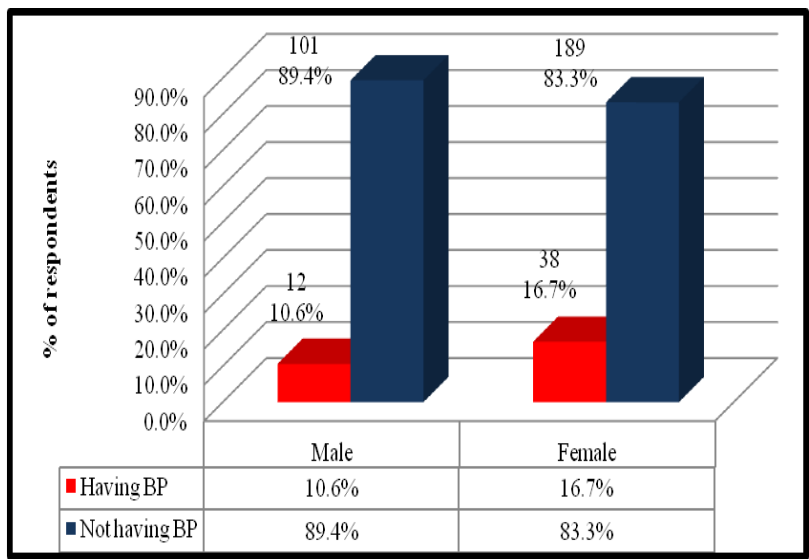

Figure 1: Males and Females Respondents Reported having $B P$

Table [2] shows the distribution of BP incidence by socio-demographic background. Of the total age group $<25$ Years (82); $5(6.1 \%)$ reported having BP while $45(17.4 \%)$ of the total age group 25+ Years (258), of the total rural residence (41); $7(17.1 \%)$ reported having BP while 23 $(11.1 \%)$ of the total urban (208) and $20(22.0 \%)$ of the total semi urban (91) residence, of the total below university level respondents (57); $13(22.8 \%)$ reported having BP while 37 $(13.1 \%)$ of the total university+ (283), of the total married (179); 29 (16.2\%) reported having BP while $12(8.5 .0 \%)$ of the total singles (142), and $9(40.9 \%)$ of the total (22) other (widowed, separated divorced, of the total not working respondents $(33) ; 6(18.2 \%)$ revealed having BP while 39 $(19.0 \%)$ of the total employees (205), of the total having familial history with BP (225), 38 (16.9\%) revealed having BP while $12(10.4 \%)$ of no family history of BP (115), of the total reported drinking Coca-Cola $(221) ; 21(9.5 \%)$ revealed having BP while 29 (24.4\%) of not drinking it (119). Significant difference was seen between the indicators of the age-group, marital status, employment and Coca-Cola intake variables.
Table 2: Distribution of Blood Pressure Incidence by Socio Demographic Background

\begin{tabular}{|c|c|c|c|c|c|c|c|}
\hline Variables & $\begin{array}{c}\text { Predicto } \\
\text { rs }\end{array}$ & $\begin{array}{c}\mathrm{Hav} \\
\text { ing } \\
\mathrm{BP}\end{array}$ & $\%$ & $\begin{array}{c}\text { Not } \\
\text { Hav } \\
\text { ing }\end{array}$ & $\%$ & Total & $\%$ \\
\hline \multirow{3}{*}{ Sex } & Male & 12 & 10.6 & 101 & 89.4 & 113 & 100 \\
\hline & Female & 38 & 16.7 & 189 & 83.3 & 227 & 100 \\
\hline & Total & 50 & 14.7 & 290 & 85.3 & 340 & 100 \\
\hline \multirow{3}{*}{ Age-group } & $\angle 25$ Yrs. & 5 & 6.1 & 77 & 93.9 & 82 & 100 \\
\hline & $25+Y_{r s}$ & 45 & 17.4 & 213 & 82.6 & 258 & 100 \\
\hline & Total & 50 & 14.7 & 290 & 85.3 & 340 & 100 \\
\hline \multirow{4}{*}{ Residence } & Rural & 7 & 17.1 & 34 & 82.9 & 41 & 100 \\
\hline & Urban & 23 & 11.1 & 185 & 88.9 & 208 & 100 \\
\hline & Semi & 20 & 22.0 & 71 & 78.0 & 91 & 100 \\
\hline & Total & 50 & 14.7 & 290 & 85.3 & 340 & 100 \\
\hline \multirow{3}{*}{ Education } & Below & 13 & 22.8 & 44 & 77.2 & 57 & 100 \\
\hline & Universit & 37 & 13.1 & 246 & 86.9 & 283 & 100 \\
\hline & \begin{tabular}{|l|} 
Total \\
\end{tabular} & 50 & 14.7 & 290 & 85.3 & 340 & 100 \\
\hline \multirow{4}{*}{$\begin{array}{l}\text { Marital } \\
\text { status }\end{array}$} & Single & 12 & 8.5 & 130 & 91.5 & 142 & 100 \\
\hline & Married & 29 & 16.2 & 147 & 82.1 & 179 & 100 \\
\hline & Other & 9 & 40.9 & 13 & 59.1 & 22 & 100 \\
\hline & Total & 50 & 14.7 & 290 & 85.3 & 340 & 100 \\
\hline \multirow{5}{*}{$\begin{array}{c}\text { Employmen } \\
t^{*}\end{array}$} & Not & 6 & 18.2 & 27 & 81.8 & 33 & 100 \\
\hline & Housewit & 3 & 10.7 & 25 & 89.3 & 28 & 100 \\
\hline & \begin{tabular}{|l|} 
Student \\
\end{tabular} & 2 & 2.7 & 72 & 97.3 & 74 & 100 \\
\hline & Employe & 39 & 19.0 & 166 & 81.0 & 205 & 100 \\
\hline & Total & 50 & 14.7 & 290 & 85.3 & 340 & 100 \\
\hline \multirow{3}{*}{$\begin{array}{c}\text { Familial } \\
\text { History } \\
\text { of BP }\end{array}$} & Yes, & 38 & 16.9 & 187 & 83.1 & 225 & 100 \\
\hline & No & 12 & 10.4 & 103 & 89.6 & 115 & 100 \\
\hline & Total & 50 & 14.7 & 290 & 85.3 & 340 & 100 \\
\hline \multirow{3}{*}{$\begin{array}{l}\text { Coca-Cola } \\
\text { consumers }\end{array}$} & Drink & 21 & 9.5 & 200 & 90.5 & 221 & 100 \\
\hline & Not drink & 29 & 24.4 & 90 & 75.6 & 119 & 100 \\
\hline & \begin{tabular}{|l|} 
Total \\
\end{tabular} & 50 & 14.7 & 290 & 85.3 & 340 & 100 \\
\hline
\end{tabular}

Significant difference $(\mathrm{P}<0.05)$

4-Multiple Logistic Regression Model Odds Socio-Demographic Predictors by Incidence of Blood Pressure

Table [3] shows the multiple logistic regression model odds socio-demographic background in relation to the incidence of BP. The socio-demographic factors predicting the onset of $\mathrm{BP}$ were the below university were at 1.9 risk $[\mathrm{OR}=1.964$, (95\% CI 0.967, 3.99)] of contracting BP while respondents with family history of $\mathrm{BP}$ were at 1.7 risk $[\mathrm{OR}=1.744(95 \%$ CI $0.873,3.485)$ ] in compare to university+ and not having family history of BP respectively.

A one unit change in the below university would increase the incidence of BP by $67.5 \%$ while by $55.6 \%$ in the familial history of BP in judge against not having BP. However, changes in each of the predictors (below university) and (having BP family history) value are not significantly associated $(\mathrm{P}>0.05)$ with the changes in the outcome variable (BP). 
International Journal of Recent Technology and Engineering (IJRTE) ISSN: 2277-3878, Volume-8 Issue-4S5, December 2019

Table 3: Multiple Logistic Regression Model Odds Socio-Demographic Predictors of Incidence of Blood Pressure

\begin{tabular}{|c|c|c|c|c|c|c|c|}
\hline $\begin{array}{l}\text { Independent } \\
\text { Variables }\end{array}$ & $\begin{array}{l}\text { Indicators of } \\
\text { independent } \\
\text { variables }\end{array}$ & $\begin{array}{l}\text { Dependent } \\
\text { variable }\end{array}$ & $\mathrm{B}$ & $\operatorname{Exp}(B)$ & $\begin{array}{l}\text { Lower } \\
\text { Bound }\end{array}$ & $\begin{array}{l}\text { Upper } \\
\text { Bound }\end{array}$ & Sig. \\
\hline \multirow{3}{*}{ Sex } & Intercept & \multirow{28}{*}{ Having BP } & -1.604 & & & & 0 \\
\hline & Males & & -0.526 & 0.591 & 0.296 & 1.181 & 0.137 \\
\hline & Females & & $0^{\mathrm{b}}$ & . & . & . & . \\
\hline \multirow{3}{*}{ Age-group } & Intercept & & -1.555 & & & & 0 \\
\hline & $<25$ years & & -1.18 & 0.307 & 0.118 & 0.803 & 0.016 \\
\hline & $25+$ years & & $0^{\mathrm{b}}$ & . & . & . & . \\
\hline \multirow{4}{*}{ Residence } & Intercept & & -1.267 & & & & 0 \\
\hline & Rural & & -0.314 & 0.731 & 0.282 & 1.895 & 0.519 \\
\hline & Urban & & -0.818 & 0.441 & 0.228 & 0.853 & 0.015 \\
\hline & Semi urban & & 0 & . & . & . & . \\
\hline \multirow{3}{*}{ Education } & Intercept & & -1.894 & & & & 0 \\
\hline & $\begin{array}{l}\text { Below } \\
\text { University }\end{array}$ & & 0.675 & 1.964 & 0.967 & 3.99 & 0.062 \\
\hline & University+ & & $0^{\mathrm{b}}$ & . & . & . & . \\
\hline \multirow[b]{4}{*}{ Marital status } & Intercept & & -0.368 & & & & 0.396 \\
\hline & Single & & -2.015 & 0.133 & 0.047 & 0.375 & 0.000 \\
\hline & Married & & -1.255 & 0.285 & 0.111 & 0.728 & 0.009 \\
\hline & $\begin{array}{l}\text { Others } \\
\text { (divorced, } \\
\text { widowed, } \\
\text { separated) }\end{array}$ & & $0^{\mathrm{b}}$ & 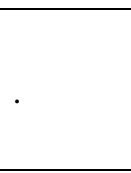 & . & . & . \\
\hline \multirow{5}{*}{ Employment } & Intercept & & -1.448 & & & & 0 \\
\hline & Not working & & -0.056 & 0.946 & 0.365 & 2.448 & 0.909 \\
\hline & House wife & & -0.672 & 0.511 & 0.147 & 1.778 & 0.291 \\
\hline & Student & & -2.135 & 0.118 & 0.028 & 0.503 & 0.004 \\
\hline & Employee & & $0^{\mathrm{b}}$ & . & . & . & . \\
\hline \multirow{3}{*}{$\begin{array}{l}\text { Familial } \\
\text { history high } \\
\text { BP }\end{array}$} & Intercept & & -2.15 & & & & 0 \\
\hline & $\begin{array}{l}\text { Family } \\
\text { history }\end{array}$ & & 0.556 & 1.744 & 0.873 & 3.485 & 0.115 \\
\hline & $\begin{array}{l}\text { No family } \\
\text { history }\end{array}$ & & $0^{\mathrm{b}}$ & . & . & . & . \\
\hline \multirow{3}{*}{$\begin{array}{l}\text { Coca-Cola } \\
\text { consumers }\end{array}$} & Intercept & & -1.133 & & & & 0.000 \\
\hline & $\begin{array}{l}\text { Drink } \\
\text { Coca-Cola }\end{array}$ & & -1.121 & 0.326 & 0.176 & 0.602 & 0.000 \\
\hline & $\begin{array}{l}\text { Not drink } \\
\text { Coca Cola }\end{array}$ & & $0^{\mathrm{b}}$ & & . & . & . \\
\hline
\end{tabular}




\section{5-Coffee Consumption Patterns by Incidence of Blood Pressure}

Table [4] shows the distribution of coffee consumption patterns by the incidence of BP. Those were $1(4.5 \%)$ of the total black coffee favorites (22), 29 (18.7\%) of the favorites of Arabica coffee (Only) (155), 23(19.7\%) of the favorites of concentrated coffee (117), $23(15.2 \%)$ of the total drink <36 ounces/ day (151), 26 (18.2\%) of the total used to drink coffee for $10+$ years (143), $28(20.9 \%)$ of the favorites of homemade coffee (134) and $6(20.7 \%)$ of the total who never drink water after coffee intake. The favorites of each of the Arabica coffee (only) and the homemade coffee were significantly $(\mathrm{P}<0.05)$ related to onset of BP.

Table 4: Distribution of Coffee Consumption Patterns by Incidence of BP

\begin{tabular}{|c|c|c|c|c|c|c|c|}
\hline \multirow{2}{*}{ Variables } & \multirow{2}{*}{ Predictors } & \multicolumn{2}{|c|}{$\begin{array}{c}\text { Having } \\
\text { BP }\end{array}$} & \multicolumn{2}{|c|}{$\begin{array}{c}\text { Not having } \\
\text { BP }\end{array}$} & \multicolumn{2}{|c|}{ Total } \\
\hline & & No. & $\%$ & No. & $\%$ & No & $\%$ \\
\hline \multirow{6}{*}{ Type } & Black coffee only & 1 & 4.5 & 21 & 95.5 & 22 & 100.0 \\
\hline & Black and/or other types & 49 & 15.4 & 269 & 84.6 & 318 & 100.0 \\
\hline & Total & 50 & 14.7 & 290 & 85.3 & 340 & 100.0 \\
\hline & Arabica coffee only & 29 & 18.7 & 126 & 81.3 & 155 & $100.0 *$ \\
\hline & Arabica and/or other types & 21 & 11.4 & 164 & 88.6 & 185 & 100.0 \\
\hline & Total & 50 & 14.7 & 290 & 85.3 & 340 & 100.0 \\
\hline \multirow{4}{*}{ Coffee concentration } & Concentrated coffee & 23 & 19.7 & 94 & 80.3 & 117 & 100.0 \\
\hline & Normal coffee & 13 & 10.8 & 107 & 89.2 & 120 & 100.0 \\
\hline & Both & 14 & 13.6 & 89 & 86.4 & 103 & 100.0 \\
\hline & Total & 50 & 14.7 & 290 & 85.3 & 340 & 100.0 \\
\hline \multirow{3}{*}{ Volume } & $36+$ ounces/day & 27 & 14.3 & 162 & 85.7 & 189 & 100.0 \\
\hline & $<36$ ounces/ day & 23 & 15.2 & 128 & 84.8 & 151 & 100.0 \\
\hline & Total & 50 & 14.7 & 290 & 85.3 & 340 & 100.0 \\
\hline \multirow{3}{*}{$\begin{array}{l}\text { Time span of coffee } \\
\text { intake }\end{array}$} & $10+$ Years & 26 & 18.2 & 117 & 81.8 & 143 & 100.0 \\
\hline & $<10$ Years & 24 & 12.2 & 173 & 87.8 & 197 & 100.0 \\
\hline & Total & 50 & 14.7 & 290 & 85.3 & 340 & 100.0 \\
\hline \multirow{4}{*}{ Coffee preparation site } & Homemade coffee & 28 & 20.9 & 106 & 79.1 & 134 & $100.0 *$ \\
\hline & Sold coffee & 2 & 8.0 & 23 & 92.0 & 25 & 100.0 \\
\hline & Both & 20 & 11.0 & 161 & 89.0 & 181 & 100.0 \\
\hline & Total & 50 & 14.7 & 290 & 85.3 & 340 & 100.0 \\
\hline \multirow{4}{*}{$\begin{array}{l}\text { Drink water after coffee } \\
\text { intake }\end{array}$} & Very Keen & 11 & 12.8 & 75 & 87.2 & 86 & 100.0 \\
\hline & Not keen & 33 & 14.7 & 192 & 85.3 & 225 & 100.0 \\
\hline & Never drink & 6 & 20.7 & 23 & 79.3 & 29 & 100.0 \\
\hline & Total & 50 & 14.7 & 290 & 85.3 & 340 & 100.0 \\
\hline
\end{tabular}

* Significantly $(\mathrm{P}<0.05)$ related to onset of BP.

\section{5- Multiple Logistic Regressions Model Odds Patterns Coffee Consumption of Having and Not Having BP}

Table [5] shows the multiple logistic regression model odds patterns of coffee consumption predictors ofy incidence of blood pressure. The consumers of Arabica coffee (only) were are at 1.79 risk $[\mathrm{OR}=1.79(95 \%$ CI $0.979,3.300]$ of contracting $\mathrm{BP}$, the consumers of strong coffee were at 1.5 $[\mathrm{OR}=1.55(95 \% \mathrm{CI} 0.7530,3.211)]$ and the consumers of homemade coffee were at 2.126 risk [OR $=1.139$ (95\% CI
2.126, 3.969] of contracting high BP in compare to consumers of Arabica and other coffee types and the favorites of both homemade and outlets' coffee selling respectively. It also shows a one unit change in the use of Arabica coffee would increase the incidence of BP by $58.6 \%$ while by $44.2 \%$ in case of using strong coffee in judge against not having BP. However, only changes in homemade predictor is significantly $(\mathrm{P}<0.05)$ associated with the changes in the outcome variable (BP). 
Table 5: Multiple Logistic Regressions Model Odds Coffee Consumption Patterns of Having and Not Having BP

\begin{tabular}{|c|c|c|c|c|c|c|c|}
\hline \multirow{2}{*}{$\begin{array}{l}\text { Independent } \\
\text { Variables }\end{array}$} & \multirow{2}{*}{$\begin{array}{c}\text { Indicators of independent } \\
\text { variables }\end{array}$} & \multirow{2}{*}{$\begin{array}{c}\text { Dependent } \\
\text { variable }\end{array}$} & \multirow{2}{*}{ B } & \multirow{2}{*}{$\operatorname{Exp}(B)$} & \multicolumn{2}{|c|}{$\begin{array}{l}\text { 95\% Confidence } \\
\text { Interval for } \operatorname{Exp}(\mathbf{B})\end{array}$} & \multirow{2}{*}{ Sig. } \\
\hline & & & & & $\begin{array}{l}\text { Lower } \\
\text { Bound }\end{array}$ & $\begin{array}{l}\text { Upper } \\
\text { Bound }\end{array}$ & \\
\hline \multirow{6}{*}{ Coffee type } & Intercept & \multirow{23}{*}{$\begin{array}{l}\text { Having } \\
\text { BP }\end{array}$} & -1.703 & & & & 0 \\
\hline & Black coffee only & & -1.342 & 0.261 & 0.034 & 1.989 & 0.195 \\
\hline & Black and/or other types & & $0^{\mathrm{b}}$ & 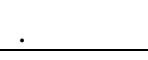 & & &. \\
\hline & Intercept & & -2.055 & & & & 0 \\
\hline & Arabica coffee only & & 0.586 & 1.797 & 0.979 & 3.300 & 0.059 \\
\hline & $\begin{array}{l}\text { Arabica and coffee and other } \\
\text { types }\end{array}$ & & $0^{\mathrm{b}}$ & & & & \\
\hline \multirow{4}{*}{$\begin{array}{l}\text { Preferable } \\
\text { of coffee } \\
\text { concentration }\end{array}$} & Intercept & & -1.85 & & & & 0 \\
\hline & Strong coffee & & 0.442 & 1.555 & 0.753 & 3.211 & 0.232 \\
\hline & Normal coffee & & -0.258 & 0.772 & 0.345 & 1.729 & 0.530 \\
\hline & Prefer both & & $0^{\mathrm{b}}$ & 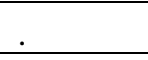 & & &. \\
\hline \multirow{3}{*}{ Volume } & Intercept & & -1.717 & & & & 0 \\
\hline & $36+$ ounce per a day & & -0.075 & 0.928 & 0.508 & 1.694 & 0.807 \\
\hline & $<36$ ounce per a day & & $0^{\mathrm{b}}$ &. & & &. \\
\hline \multirow{3}{*}{ Time span } & Intercept & & -1.504 & & & & 0 \\
\hline & $10+$ Years & & -0.471 & 0.624 & 0.342 & 1.14 & 0.125 \\
\hline & $<10$ Years & & $0^{\mathrm{b}}$ &. & & 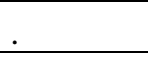 &. \\
\hline \multirow{4}{*}{ Intake site } & Intercept & & -2.086 & & & & 0 \\
\hline & Homemade coffee & & 0.754 & 2.126 & 1.139 & 3.969 & 0.018 \\
\hline & Coffee selling outlets & & -0.357 & 0.7 & 0.153 & 3.193 & 0.645 \\
\hline & Both & & $0^{\mathrm{b}}$ &. & & & 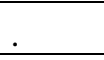 \\
\hline \multirow{3}{*}{ Water drink } & Intercept & & -1.344 & & & & 0.003 \\
\hline & $\begin{array}{l}\text { Very keen to drink water after } \\
\text { coffee }\end{array}$ & & -0.576 & 0.562 & 0.187 & 1.687 & 0.304 \\
\hline & Never drink water after coffee & & -0.417 & 0.659 & 0.249 & 1.741 & 0.400 \\
\hline
\end{tabular}

\section{DISCUSSION}

A number of research studies have been conducted to determine whether there is a co- relation between coffee consumption and blood pressure. This descriptive analytical study is one of these studies. It hypothesized that the high BP is inter-related with the coffee consumption behavior's patterns and the socio-demographic background of respondents. Most of the studies could not prove neither causal or significant co-link between coffee consumption nor significant increase in blood pressure increase . Gadsby etal reported that, although caffeine consumption is associated with increased BP, however relationship between them is not well proved and medical research has not confirmed this.

Higdon etal reported that there is slight evidence of health hazards and some evidence of health benefits of coffee drinking.

Andersen etal study concluded that coffee consumption is a major source of dietary antioxidants that may inhibit inflammation and thereby reduce the risk of cardiovascular and other inflammatory diseases in postmenopausal women. O'Keefe etal reported that 2 to 3 coffee cups per day is safe. Besides, the coffee consumption may reduce the risk of type-2 diabetes and high blood pressure.
Nurminen etal reported that in epidemiological studies, causal relationships were difficult to prove existence of correlation between coffee consumption and BP increase. Landin paper summarizes that data from cross-sectional studies suggest an inverse linear or U-shaped association of habitual coffee use with BP in different populations, and that most evidence suggests that regular intake of caffeinated coffee does not increase the risk of hypertension.

The randomized controlled trials reported by Geleijnse that there is presence of several underlying biological mechanisms that attributed to BP-raising and that the exact relationship nature between coffee and $\mathrm{BP}$ is still uncertain and that most data suggests that habitual intake of caffeinated coffee does not increase the risk of hypertension.

Kozuma etal study reported that the water-soluble green coffee bean extract has a blood pressure-lowering effect in patients with mild hypertension.

Verma conducted a study on elettaria cardamom Maton. The study concluded that small cardamom can effectively reduce BP. 
The Iranian registry of clinical trials aimed at identifying the effect of cardamom on blood lipids, blood sugar indices, and BP in per-diabetic females .Observation shows no significant decrease in systolic and diastolic BP.

Badkook etal, 2013 study aimed at identifying the effects of daily consumption of Arabic coffee with cardamom adds, on BP and other health. The study concluded that daily consumption of $500 \mathrm{ml}$ of Arabica coffee with either regular or high doses of cardamom may be a risk factor of heart disease and stroke especially with a high dose of cardamom, although it does not affect BP and inflammation.

conducted the systematic review and meta-analysis concluded by Steffen etal concluded that recommendation with or against coffee consumption in relation to BP could not be made because of the quality of the research evidence. Besides, there were no statistically significant effects of coffee consumption on onset of BP or the risk of high BP.

Palatini etal concluded that the risk of hypertensive associated with coffee intake varies according to CYP1A2 genotype and is not generic.

As for the studies reported the co-relation between coffee consumption and high BP Gadsby etal reported that too much consumption of coffee (five or more cups a day) can cause a small increase in $\mathrm{BP}(2 / 1 \mathrm{~mm} \mathrm{Hg})$ whether having BP or not, especially if combined with a prolonged intake that can go up to several months.

Klag etal (2002) showed that consumption of one cup of coffee per day increased the systolic BP by $0.19 \mathrm{mmHg}$ and the diastolic pressure by $0.27 \mathrm{mmHg}$ but it is insignificantly associated with rising BP, which plays a small role in the development of hypertension.

Higdon etal reported consumption of 3-4 coffee cups per/day will provide $300-400 \mathrm{mg} / \mathrm{d}$ of caffeine constitute possible health risk of coffee intake for adults including vulnerable people with hypertension, children, adolescents, and the elderly.

However, this study showed significant relationships between high BP and consumption of Arabica coffee (only), favorable of strong coffee and the preference of homemade coffee.

Favorable of strong and homemade coffee were seen to be prognosis factors of high BP.

The below university and having a family member/s with history of BP were seen to be prognosis factors of high $\mathrm{BP}$ also.

\section{CONCLUSION}

This study concluded that the consumers of each of the Arabica coffee (only) were are at 1.79 risk in contracting high $\mathrm{BP}$, while at 1.5 and 2.1 were the favorites of each of the strong coffee, and the homemade coffee in compare to consumers of the Arabica and the other coffee types, and the favorites of both the homemade and the outlets' coffee selling, and the favorites of normal coffee respectively. The homemade predictor value was significantly $(\mathrm{P}<0.05)$ related to changes in the outcome value (high BP). Consumption of each of the homemade and strong coffee were seen to be prognosis factors of contracting $4+$ signs and symptoms suggesting high BP as well.

The coffee consumption patterns in relation to having 4+ signs and symptoms suggesting high BP, all coffee consumption patterns were seen to be a prognosis factors of contracting 4+ signs and symptoms suggesting BP except from drinking Arabica coffee (only) and drinking Coca-cola.
As for the socio-demographic background, family history of having high BP and below university were seen to be at 1.7 and 1.9 risk of contracting high $\mathrm{BP}$ in compare to university+ and not having family history of BP respectively. However, they were not significantly associated $(\mathrm{P}>0.05)$ with the outcome variable (BP).

\section{REFERENCES}

1. WHO, W. H. O.-. Hypertention. WHO - Hypertention. Retrieved July 7th 2019, from https://www.who.int/topics/hypertension/en/

2. John Warner, M. D., MBA; President, American Heart Association, 2017-18. (November 13,2017). New Hypertension Guideline Updates How We Measure and Treat High Blood Pressure.

3. Treur, J. L., Taylor, A. E., Ware, J. J., McMahon, G., Hottenga, J. J., Baselmans, B. M., . . Vink, J. M. (2016). Associations between smoking and caffeine consumption in two European cohorts. Addiction, 111(6), 1059-1068.

4. Speer, K., \& Kölling-Speer, I. (2006). The lipid fraction of the coffee bean. Brazilian Journal of Plant Physiology, 18(1), 201-216.

5. Barone, J., \& Roberts, H. (1996). Caffeine consumption. Food and chemical toxicology, 34(1), 119-129.

6. Andersen, L. F., Jacobs Jr, D. R., Carlsen, M. H., \& Blomhoff, R. (2006).

7. Nurminen, M. L., Niittynen, L., Korpela, R., \& Vapaatalo, H. (1999). Coffee, caffeine and blood pressure: a critical review. Eur J Clin Nutr, 53(11), 831-839. doi: 10.1038/sj.ejen. 1600899

8. Higdon, J. V., \& Frei, B. (2006). Coffee and health: a review of recent human research. Critical reviews in food science and nutrition, 46(2), 101-123.

9. O'Keefe, J. H., Bhatti, S. K., Patil, H. R., DiNicolantonio, J. J., Lucan, S. C., \& Lavie, C. J. (2013). Effects of Habitual Coffee Consumption on Cardiometabolic Disease, Cardiovascular Health, and All-Cause Mortality. Journal of the American College of Cardiology, 62(12), 1043-1051. doi: 10.1016/j.jacc.2013.06.035

10. Palatini, P., Ceolotto, G., Ragazzo, F., Dorigatti, F., Saladini, F., Papparella, I., . . . Santonastaso, M. (2009). CYP1A2 genotype modifies the association between coffee intake and the risk of hypertension. Journal of hypertension, 27(8), 1594-1601.

11. Nurminen, M. L., Niittynen, L., Korpela, R., \& Vapaatalo, H. (1999). Coffee, caffeine and blood pressure: a critical review. Eur J Clin Nutr, 53(11), 831-839. doi: 10.1038/sj.ejcn. 1600899

12. Gadsby, R., \& Roger Gadsby, M. (2013). Managing hypertension in type 2 diabetes. Diabetes \& Primary Care, 5, 2015.

13. 13.Robertson, D., Frölich, J. C., Carr, R. K., Watson, J. T., Hollifield, J. W., Shand, D. G., \& Oates, J. A. (1978). Effects of caffeine on plasma renin activity, catecholamines and blood pressure. New England Journal of Medicine, 298(4), 181-186.

14. Kozuma, K., Tsuchiya, S., Kohori, J., Hase, T., \& Tokimitsu, I. (2005). Antihypertensive Effect of Green Coffee Bean Extract on Mildly Hypertensive Subjects. Hypertension Research, 28(9), 711-718. doi: 10.1291/hypres.28.711

15. Landin-Wllhelmsen, K., Wllhelmsen, L., Lappast, G., Rosen, T., Lindstedt, G., Lundberg, P. A., \& Bengtsson, B. Á. (1994). Serum insulin-like growth factor I in a random population sample of men and women: relation to age, sex, smoking habits, coffee consumption and physical activity, blood pressure and concentrations of plasma lipids, fibrinogen, parathyroid hormone and osteocalcin. Clinical Endocrinology, 41(3), 351-357. 
16. Geleijnse. (2008). Habitual coffee consumption and blood pressure: an epidemiological perspective. Vascular health and risk management. NBI MPC, , 4(5), 963-970. doi:10.2147/vhrm.s3055.

17. 17.Steffen, M., Kuhle, C., Hensrud, D., Erwin, P. J., \& Murad, M. H. (2012). The effect of coffee consumption on blood pressure and the development of hypertension: a systematic review and meta-analysis. Journal of hypertension, 30(12), 2245-2254

18. Klag, M. J., Wang, N.-Y., Meoni, L. A., Brancati, F. L., Cooper, L. A., Liang, K.-Y., . . . Ford, D. E. (2002). Coffee intake and risk of hypertension: the Johns Hopkins precursors study. Archives of Internal Medicine, 162(6), 657-662.

19. Verma, S. K., Jain, V., \& Katewa, S. S. . ( 2009 ). Blood pressure lowering, fibrinolysis enhancing and antioxidant activities of cardamom (Elettaria cardamomum).

20. Fatemeh, Y., Siassi, F., Rahimi, A., Koohdani, F., Doostan, F., Qorbani, M., \& Sotoudeh, G.X. (2017).

21. Badkook, M. M., \& Shrourou, R. M. (2013). Arabic coffee with two doses of cardamom: effects on health biomarkers in healthy women. Int J Nutr Food Sci, 2(6), 280-286. 